\title{
Promoting School Health Education: A Lesson from the COVID-19 Pandemic
}

\author{
Mohamed Lounis ${ }^{1 *}$ (1)
}

${ }^{1}$ University of Djelfa, ALGERIA

*Corresponding Author: m.lounis@univ-djelfa.dz

Citation: Lounis, M. (2020). Promoting School Health Education: A Lesson from the COVID-19 Pandemic. Contemporary Mathematics and Science Education, 1(2), ep20009. https://doi.org/10.30935/conmaths/8579

\begin{abstract}
The world is facing to a new pandemic called coronavirus disease 2019 (COVID-19). In the absence of an efficient treatment or vaccines, Governments have adopted different preventive measures to limit the spread of this disease such as social distancing, mask wearing and quarantine. However, the response of people to these measures was one of the most obstacle in their application demonstrating a missing link in the concept of health education. The current manuscript describe the importance of school health education and the necessity of investing in this concept as a lesson from the COVID-19 pandemic.
\end{abstract}

Keywords: school health education, health promotion, COVID-19

Received: 13 Jul. 2020 • Accepted: 5 Aug. 2020

The novel Coronavirus respiratory disease 2019 (COVID-19) has not stopped expanding and impressing the world since it started in Wuhan (china) on December 2019 (Lounis, 2020). With more than 8 millions positive cases in more than 213 countries and regions and a current estimated case-fatality rate of about $4.4 \%$, the disease has exceeded all expectations (Statistica, 2020).

To burden the curve of the disease and to limit the spread of the virus, National authorities have adopted a set of different preventive measures. These measures are mainly based from the WHO recommendations and adapted according to countries's capacities. They varied from individual measures such as hand hygiene, mask wearing and social distancing to the community or national level such as quarantine and total or partial lockdown. However, the response of people was one of the most important obstacles in the application of these measures. Except some Pacific South Asian countries where people have an experience with epidemic diseases, these responses were generally characterized by the lightening of these measures like social distancing and the correct mask wearing and hand washing demonstrate a weak health education even in the developed and the under developed countries. Also, the number of Tv, radio and social media podcasts regarding the "correct" manner of coughing, sneezing, hand washing and mask wearing demonstrate that there is a missing link about this concept. That's why; investing in health education especially in schools may be one of the important lessons to learn from this pandemic.

As a definition, health education is any combination of learning experiences designed to facilitate voluntary actions conducive to health (Green \& Iverson, 1982). The World Health Organization (WHO) defines health education as "consciously constructed opportunities for learning involving some form of communication designed to improve health literacy, including improving knowledge, and developing life skills, which are conducive to individual and community health". It is not limited to the dissemination of health-related information but also fostering the motivation, skills and confidence necessary to take action to improve health and the communication of information concerning the underlying social, economic and environmental conditions impacting on health, as well as individual risk factors and risk behaviours, and use of the health care system (Bandawe, 2009).

The overall goal of health education is not only to increase knowledge about personal health behavior but also to develop skills that demonstrate the political feasibility and organizational possibilities of various forms of action to address social, economic and environmental determinants of health. Globally, health education is working to promote health, prevent disease, disability, and premature death (Torabi \& Yang, 2000).

According to Coalition of National Health Education Organizations the objectives of health education are:

- Improving the health status of individuals, families, communities, states, and the nation

- Enhancing the quality of life for all people

- Reducing premature deaths

- Reducing the costs (both financial and human) that individuals, employers, families, insurance companies, medical facilities, communities, states and nations would spend on medical treatment by focusing on prevention (CNHEO, 2009). 
Several approaches to health education are currently identified. Based on theoretical and philosophical suppositions these different approaches have been divided on three main chapters including:

- The conventional health education, which emphasizes knowledge acquisition.

- The health communication, which searches to change human behavior and environmental factors with the objective to market changes in health-related practices and subsequently, health status (including the social marketing approach, which attempts to influence a socially beneficial idea or the use of certain products)

- The health education for empowerment which aims at empowering the target population (Bandawe, 2009).

To introduce these concepts in the targeted population several channels could be used where schools, the workplace and medical care facilities are the most common.

School health education is considered as the unique and the most important way to improve the health and educational outcomes of children and adolescents. With Over one billion pupils enrolled in schools in the world, and through them their communities and immediate families, schools are the broadest and the deepest channel for assign information to citizens in the world. According to the WHO, Schools are one of the most organized and powerful systems in society to influence the health and well being of those who come into contact with it (WHO, 2012). Children spend most of their time outside their homes in schools; therefore, school is the best setting to tell them information and thus organize their knowledge, skills, habits, and beliefs (Au et al., 2010).

The importance of school health education in promoting the health of young people and contributing to the overall public health has been recognized worldwide (Torabi \& Yang, 2000). Several researchers reported school-based health education had positive effects on health related knowledge, attitudes, and practices (Cho, 2009; Kim \& Park, 2013; Tomokawa et al., 2020).

In this way, the World Health Organization (WHO) introduced since 1986 the concept of health-promoting schools (HPS) as an approach to promoting health in pupils, school personnel, families, and entire communities through schools (Gulzar et al., 2017). Later, Center for Disease Control (CDC) in the USA has developed a comprehensive curriculum for health education in schools. Also, multiples ministries of education and health in some Asian and Pacific countries have jointly revised comprehensive health curricula for different age groups and teachers (Gulzar et al., 2017).

However, these concepts remains globally often characterized by relatively low priority, fragmentation, and a lack of coordination (Bartelink et al., 2019).

At last we can say that the improvement of school health education practices would be more than necessary to improve and introduce the concept of health education in the community which will be an investing in the struggle of the future health risks.

\section{REFERENCES}

Au, W. H., Suen, L. K. P., \& Wok, K. Y. L. (2010). Handwashing programme in kindergarten: a pilot study. Health Education, 110(1), 5-16. https://doi.org/10.1108/09654281011008717

Bandawe, C. (2009). A synopsis of the field of health education in Malawi. Malawi Medical Journal, 21(4), 159-162. https://doi.org/10.4314/mmj.v21i4.49641

Bartelink, N. H. M., van Assema, P., Jansen, M. W. J., Savelberg, H. H. C. M., Moore, G. F., Hawkins, J., \& Kremers, S. P. J. (2019). Process evaluation of the Healthy Primary School of the Future: the key learning points. BMC Public Health, 19, 698. https://doi.org/10.1186/s12889-019-6947-2

Cho, C.-M. (2009). The Effects of Regular Health Education affecting Health Knowledge, Attitude, Behavior on Middle School students. J. of Korean Soc. of School Health, 22(2), 49-59.

Coalition of National Health Education Organizations (CNHEO). (2009). Health Education. Retrieved on 12 May 2020 from http://www.cnheo.org/files/health_ed.pdf

Green, L. W., \& Iverson, D. C. (1982). School health education. Ann. Re. Public Health., 3, 321-338. https://doi.org/10.1146/ annurev.pu.03.050182.001541

Gulzar, S. A., Nayani, P., Husain, S. S., \& Khan, A. (2017). Development of the School Health Education Program from the perspective of Comprehensive School Health Model: an example at a Higher Secondary School of Karachi, Pakistan. Taiwan J Public Health, 36(6), 545-555. https://doi.org/10.6288/TJPH201736105118

Kim, Y. I., \& Park, E. (2013). The Effects of Health Education on Health Knowledge and Health Promoting Behaviors in Elementary School Students. J Korean Soc School Health, 26(2), 55-61.

Lounis, M. (2020). A Descriptive Study of the Current Situation of COVID-19 in Algeria. Electronic Journal of General Medicine, 17(6), em253. https://doi.org/10.29333/ejgm/8287

Statista (2020). Number of novel coronavirus (COVID-19) deaths worldwide as of October 1, 2020, by country. Retrieved on 13 July 2020 from https://www.statista.com/statistics/1093256/novel-coronavirus2019ncov-deaths-worldwide-by-country/

Tomokawa, S., Asakura, T., Njenga, S. M., Njomo, D. W., Takeuch, R., Akiyama, T., Kazama, H., Mutua, A., Barnett, W., Henzan, H., Shimada, M., Ichinose, Y., Kamiya, Y., Kaneko, S., Miyake, K., \& Kobayashi, J. (2020). Examining the appropriateness and reliability of the strategy of the Kenyan Comprehensive School Health Program. Global Health Promotion. First Published 30 May 2020. https://doi.org/10.1177/1757975920917976

Torabi, M. R., \& Yang, J. Z. (2000). Comprehensive School Health Model: An Integrated School Health Education and Physical Education Program. ICPE 2000 Proceedings, pp. 89-104.

World Health Organization (WHO). (2012). Health education: theoretical concepts, effective strategies and core competencies. A foundation document to guide capacity development of health educators. WHO Library Cataloguing in Publication DataRegional Office for the Eastern Mediterranean. Retrieved from https://apps.who.int/iris/ bitstream/handle/10665/119953/EMRPUB_2012_EN_1362.pdf?s equence $=1$ \&isAllowed $=\mathrm{y}$ 